\title{
LAS CASAS DEL PORVENIR: \\ NACIÓN Y NARRACIÓN EN EL ENSAYO PUERTORRIQUEÑO
}

POR

\author{
MARÍA ELENA RODRÍGUEZ CASTRO \\ Universidad de Puerto Rico
}

A Rubén Rtos Avila

Aveces la casa del porvenir es la sólida, más clara, más vasta que todas las casas del pasado.

(Gastón Bachelard, La poética del espacio)

\section{LA NACIÓN COMO RELATO}

Cualquier lector interesado en la historia cultural del Puerto Rico contemporáneo se encuentra de inmediato ante su hábito más persistente: la articulación y defensa dela identidad nacional. Textos creativos o deinvestigación -nostálgicos o militantes, emotivos o académicos, personales o programáticossurgen o se orientan hacia ese objetivo. Algunos, inclusive, anunciando su resolución.

Ese proceso se anudó desde las primeras décadas de este siglo a la formación de un precario pero moderno campo intelectual, en cuyas instituciones, agentes y discursos se gestó un relato de y para la nación. En el marco de una nueva relación colonial y desde los círculos letrados de los núcleos urbanos, alarmados por las implicaciones tanto reales como simbólicas del cambio de soberanía y por la emergencia de nuevos sectores sociales, los intelectuales puertorriqueños fueron definiendo una ideología y una práctica social y literaria. ${ }^{1}$ En la misma trazaron sus límites respecto a otros campos de poder y se otorgaron sus modos específicos de legitimación. ${ }^{2}$ En una retórica modelada en el discurso de la crisis

\footnotetext{
1 Trazar las condiciones de produccion de ese discurso exige restituir sus diversos contextos: social, económico y político; intelectual y estético; y el de su recepción. Dicho esfuerzo se inició en mi tesis doctoral La escritura de lo nacional y los intelectuales puertorriqueños. Princeton University: 1988 y se ampliará en un trabajo más amplio en preparacion. Ver de Arcadio Díaz Quiñones, "Recordando el futuro imaginario: la escritura histórica en la década del treinta". En Sin Nombre XIV( abril-junio 1984) 1635.

2 Sobre este tema ver Pierre Bourdieu, "Campo intelectual y proyecto creador" en Problemas del estructuralismo (México: Siglo XXI, 1966) 135-182. En América Latina,
} 
se presentaron ante una sociedad en cambio como índices de permanencia y continuidad, custodios de una cultura concebida como memoria colectiva; ante los intereses materiales que asociaron a dicha transformación se presentaron como una voz autorizada y confiable, como la conciencia moral de su sociedad; ante la especialización y heterogeneidad resultantes de la modernización se presentaron como un factor de orden y cohesión. ${ }^{3}$ Sin embargo, y a pesar de la máscara del desinterés tras la que escudaron sus discursos, poseían un capital tan especializado como los nuevos rumbos que tomaba la sociedad insular: los bienes culturales y el lenguaje en que éstos se expresan. También fue precisamente en la crítica de la especialización que el campo letrado se modernizó y se trasladó de la bohemia del café, el taller del periódico y la revista modernista a las profesiones literarias, las cátedras universitarias y las academias. ${ }^{4}$ Instaurada la especialización en el interior mismo del campo letrado, diseñaron privadamente modelos culturales destinados a conformar ideologías públicas.

Eran años vertiginosos. De reorientación del modelo de producción de un capitalismo agrario a un capitalismo industrial, del creciente rol de las corporaciones azucareras -en su mayoría de capital ausentista norteamericano-y del incremento de la actividad bancaria y financiera. De la búsqueda de legitimación del modelo político que condujo en el orden externo a la adopción de la política del Nuevo Trato y la concesión de tímidas reformas y, en el orden interno, a una compleja red de pugnas y alianzas de las principales fuerzas políticas. De cambios e inestabilidad en los patrones tradicionales de composición social. La modernización era, sin duda, el signo de los nuevos tiempos. ${ }^{5}$

Ángel Rama ha estudiado cómo, a diferencia del caso europeo, la autonomia intelectual con respecto al Estado es s6lo relativa. Véase La ciudad letrada (New Hamphire: Ediciones del Norte, 1984).

${ }^{3}$ El discurso de la crisis fue común al culturalismo nacionalista latinoamericano de la época. Se argumentaba que un déficit moral había resultado del crecimiento económico: un desajuste de los valores, estructuras y relaciones tradicionales que exigia del intelectual un rol interventor, una vuelta a los negocios públicos. Ver Pedro Henríquez Ureña, Las corrientes literarias de América Latina (México: Fondo de Cultura Económica, 1978). Pero, y cito de Jürgen Habermas, "La crisis es inseparable de la percepción interior de quien la padece"; lo que hace necesario diferenciar entre ideologías de crisis y experiencias genuinas de crisis. Véase Problemas de legitimación en el capitalismo tardio (Buenos Aires: EditorialAmorrortu, 1973) 15. Esto es, lo que fue en gran medida la crisis de una minoria letrada de la burguesía criolla se proyectó como una crisis nacional que amenazaba la integración y la identidad social.

4 Sobre la crítica de la especialización y los intelectuales latinoamericanos ver de Julio Ramos, Desencuentros de la modernidad en América Latina: Literatura y politica en el siglo XIX (México: Fondo de Cultura Económica, 1990).

- Una exposición sucinta de los procesos y transformaciones que caracterizan ese periodo la ofrece José Punsoda en Decentering Puerto Rico: The Industrial Decentralization Policy. Tesis doctoral: Rutgers University, 1990. 
En ese proceso el ensayo, una escritura abierta pero ordenadora, oscilante entre la voluntad de verdad de los discursos objetivos y la expresividad del arte, fue uno de los modos específicos que asumió la intervención letrada. En el espacio del intelectual sin estado, una posición que problematiza los cimientos de construcción de fuertes identidades nacionales - sus comienzos, su linaje, su sistema de autoridades y tradiciones tanto fundantes como interpretativas-se fabularon proyectos nacionales y se inauguraron los mitos y gestos que aún definen lo puertorriqueño. Incubadores de utopías para la nación, espacios discursivos inclusivos y armónicos donde se funde el lenguaje público y el privado, han sido nuestras casas del porvenir.

Insularismo, publicado en 1934 por Antonio S. Pedreira es sin duda el texto faro de la ensayística de su época. Heredero de los intensos debates que le precedieron, los cuales encontraron su mejor expresión en las revistas literarias Revista de las Antillas (1913-14) e Indice (1929-31), se distingue al subordinar las variantes antillanistas e hispanistas al diseño central de su propuesta: lo criollo. ${ }^{6}$ Es bajo esa premisa que leo Insularismo no como un texto fundacional, sino como un texto institucionalizador de una interpretación cul tural articulada ya a alturas de 1934. Un texto canónico y canonizador, que exhibe y discute simultáneamente su propia legitimación, la casa discursiva de la reflexión nacional. ${ }^{7}$ Insularismo codificó y prestigió no sólo un entramado para la nación, también un modo de narrarla: un sistema de tópicos, imágenes y estrategias narrativas que resistieron la repetición y el desgaste de sus contenidosideológicos excediendo las fronteras del marco letrado y alojándose permanentemente en

- Un debate que se debe relacionar con la serie amplia del culturalismo nacional latinoamericano y los ensayos, entre otros, de Ricardo Rojas, José Vasconcelos, Samuel Ramos, Carlos Mariátegui, Pedro Henriquez Ureña, Fernando Ortiz y Jorge Mañach. En Puerto Rico fueron Prontuario historico de Puerto Rico (1935) de Tomás Blanco, "Problemas de la cultura puertorriqueñan (1935) de Emilio S. Belaval y El despertar de un pueblo (1940) de Vicente Géigel Polanco. Sobre Blanco ver los ensayos de Arcadio Díaz Quiñones "Tomás Blanco: historia, racismo, esclavitud" en Tomás Blanco, El prejuicio racial en Puerto Rico. Río Piedras: Huracán, 1985 y "Tomás Blanco: la reinvención de la tradición". Boletin del Centro de Investigaciones Historicas de la Universidad de Puerto Rico 4 (19881989) 147-182. Sobre la función de las revistas ver mi artículo "Tradicion y modernidad: el intelectual puertorriqueño ante la década del treinta". Boletín del Centro de Investigaciones Historicas de la Universidad de Puerto Rico 3 (1987-1988) 45-65.

${ }^{7}$ Ver de Juan Gelpi "El clásico y la reescritura: Insularismo en las páginas de La guaracha del Macho Camacho", incluido en este número. Por otro lado, la canonización de un texto no s6́lo responde a las lecturas de su propia comunidad intelectual sino, también, al control institucional de su interpretación. De acuerdo a Frank Kermode, instituciones que le proveen de una existencia social como las academias y el estado suponen una lectura diferencial, que absorbe y descarta textos, participando activamente en la formulación de una memoria cultural. Ver "Institutional Control of Interpretation" en The Art of Telling (Cambridge: Harvard University Press, 1983) 168-184. 
el imaginario puertorriqueño. Se podría aducir, al estilo de los nuevos lenguajes técnicos de los cuales Insularismo se distanció a al tura de los treinta, que el país sigue "insularizado" a pesar del "revestimiento" de cuatro fachadas que González le echará en su colección de ensayos El país decuatro pisos de 1980, un texto que, al igual que Insularismo, unió a la reflexión su urgencia de actuar en el contexto social e intelectual de su época.

Precisamente el diálogo conflictivo entre ambos ensayos es el pretexto de estas páginas. Puntos equidistantes de una misma serie discursiva que comprende otros ensayos y cuyo centro de reflexión fue la identidad nacional encontraron en la escritura expositiva la forma perfecta de lo que Jean-Francois Lyotard ha calificado de metanarrativas de la modernidad; esto es, grandes relatos unificadores o legitimadores fundamentados en la autoridad y/o el consenso. ${ }^{8}$ Narrativas cuya naturaleza puede ser especulativa o emancipatoria conjugan, en la constitución hrbrida del ensayo, la indagación por el ser y el destino de las formaciones nacionales. En esa medida, aunque Insularismo y El país de cuatro pisos se presenten como versión y contraversión, comparten la retórica propia del metadiscurso de lo nacional; juegos de lenguaje que en momentos afilian, no sus propuestas, sino los fundamentos ideológicos de las mismas.

Ya había mencionado cómo estos relatos se configuran como "casas del porvenir", una imagen privilegiada de la inscripción nacional. Me detengo en la exploración de sus posibilidades de evocación y asociación. En un texto ya clásico sobre el tema, Gastón Bachelard propone la casa como la morada del alma, un espacio figurativo en el cual: "no solamente nuestros recuerdos sino también nuestros olvidos están alojados".9 En su postulación de la imagen, Bachelard distingue sus cualidades: los valores de intimidad del espacio interior, el reconocimiento de su unidad y complejidad en la búsqueda de integrar sus valores particulares en un valor fundamental, la casa como un cuerpo de imágenes que dan al hombre razones o ilusiones de estabilidad, y los valores de protección de la casa contra las fuerzas que la asaltan. En el marco de la ensayística latinoamericana la imagen de la casa como morada del alma asumió una connotación propia de los debates de esa ensayistica: se trataba del alma nacional y, por extensión, de lo que ya en un texto vital a las guerras de independencia se llamó la "grande familia de hermanos" que habitarian esas casas. ${ }^{10}$ La analogía entre ambas posibilidades de la imagen -alma personal/

The Postmodern Condition: A Report on Knowledge. Minneapolis: University of Minnesota Press, 1984.

- Véase La paética del espacio (México: Fondo de Cultura Económica, 1965) 29.

${ }^{10}$ Me refiero a "Carta a los españoles americanos" de 1792 de Juan Pablo Viscardo, 60. Incluido en Pensamiento polttico de la emancipación, edición de José Luis Romero (Caracas: Ayacucho, 1977). El uso extendido de esta imagen se estudia en Desencuentros de la modernidad en América Latina y en La escritura de lo nacional y los intelectuales puertorriqueños, aqui citados 
alma colectiva - descansa en gran medida en las cualidades que Bachelard había destacado. Pero su centralidad en el ensayo nacional se explica, también, en lo que Edward Said ha calificado como uno de los signos característicos de la cultura moderna: el paso de la filiación a la afiliación como garantía de creación y traspaso de vínculos de identidad. ${ }^{11}$ En ese desplazamiento la metáfora de la casa familiar amplía su campo semántico: depósito de la tradición, es el espacio más propicio para modular el cambio y asegurar, a su vez, la permanencia y la transmisión de un legado. Así, en un lenguaje sugerente del espacio y las relaciones familiares, la trama de Insularismo se articula como el lugar de encuentro entre la casa de la cultura y la casa nacional, "la vieja casa solariega de la cultura patria" de los influyentes editoriales de Índice, la revista en la cual los treintistas ensayaron su propuesta nacional. ${ }^{12}$

Pero el diseño de $E l$ país de cuatro pisos, un ensayo que se distancia casi medio siglo de Insularismo, no se reconoce ya en las líneas amables de "la vieja casa solariega". Su arquitectura responde más bien al estilo del nuevo gusto por lo vertical del Puerto Rico posterior al desarrollismo. Sin embargo, si bien una casa no es un edificio, la diferencia parece insistir sobre la vigencia de la espacialidad de la imagen nacional y a la sobrevivencia de su función emblemática. En Insularismo el paradigma de la puertorriqueñidad se modelaba en "... el pasado cuando la tierra era plural y cobraba su mejor expresión entre el paréntesis que formaban el estanciero y el poeta" ${ }^{13}$ Tierra y letras fundidas en la evocación de la época dorada de la hacienda cafetalera decimonónica, lejana y periférica, sin embargo, a la realidad cada vez más urbana e industrializada de los treinta. Mientras en el ensayo de González lo puertorriqueño es un compartimiento de un edificio mayor y de reciente construcción: la comunidad caribeña "mestiza, popular y democrática". Lo cierto es que ambos ensayos descansan sobre variantes de la metáfora de la casa y sus connotaciones: un espacio de cohesión interna en cuyos límites las pequeñas desavenencias y las diferencias particulares se dirimen en la pertenencia a una identidad común; un espacio que también demarcaba sus exteriores.

Además la imagen propiciaba otro proceso figurativo: la contaminación por analogía entre casa cultural y casa nacional. Ya fuera desde el aula de la cultura

${ }^{11}$ La afiliación funciona como un orden compensatorio a la disolución de las relaciones filiales conservando el sistema de sus ideas y valores:

Thus if a filial relationship was held together by natural bonds and natural forms of authority -involving obedience, fear, love, respect and instinctual conflict- the new affiliative relationship changes these bonds into whatseems to be transpersonal forms - such as guild consciousness, consensus ... and the hegemony of a dominant culture.

En "Secular Criticism", The World, the Text and the Critic (Cambridge: Harvard University Press, 1985) 17.

12 "Aterrizaje", Indice 11 (18 de febrero de 1930).

${ }^{13}$ Obras de Antonio S. Pedreira I (San Juan: Instituto de Cultura Puertorriqueña, 1970) 45. Toda cita posterior refiere a esta edición e indicará su número de página a continuación. 
humanista desde el cual Pedreira se dirige a su "juventud dorada", o desde el aula politizada en que se instala González, estas casas discursivas albergaron tanto la trama como los personajes y destinatarios de sus respectivas versiones -criollismo o antillanismo- en la ilusión de que sólo hay un lugar de identidad nacional y, concurrentemente, una sola versión legítima que lo represente.

Otra afinidad la traza el cruce en la voz narrativa de las modalidades que Mikhail Bakhtin designó como palabra autoritaria y palabra de convicción interna. La primera es un discurso externo: es palabra moral, religiosa, política; la voz del padre, del maestro, del adulto. ${ }^{14}$ La segunda, en cambio, carece de ese reconocimiento social o cultural anterior al texto; su capacidad de interpelación depende sólo del grado de empatía que desarrolle con su lector. La primera se asienta en una autoridad que se considera superior para mostrar e imponer su verdad -instituciones, tradiciones, valores-y demandar una alianza incondicional. La segunda se abre al dialogismo contextual y a la tensión con otros discursos de convicción interna que integran el texto auspiciando un juego interpretativo más libre.

El cruce entre ambas posibilidades discursivas, la palabra autoritaria y la de convicción interna, le dotó a la ensayística nacional de un potencial interpelativo dúctil a la formación de una conciencia nacional. A la vez que habilitaba el reconocimiento en los discursos ya hechos y autorizados de la cultura, aminoraba la distancia operativa de los mismos al abrir el debate a los espacios y circunstancias del presente. La estrategia era necesaria para la finalidad de estas metanarrativas unificadoras, constructos mediadores entre la experiencia real de la comunidad social y su diseño verbal. ${ }^{15}$ Esta retórica compartida, en parte por las exigencias del género, en parte por el proyecto ideológico que guían estos ensayos y, en parte, por ser relatos - de una modernidad que se piensa en términos de una sociedad orgánica, susceptible a diagnosis y recuperación, con límites y discursos previsibles y permisibles, es el eje que organiza mi lectura de Insularismo y $E l$ pais de cuatro pisos. El recurso a la voz magisterial que regula tramas, la imaginería espacial que auspicia los tópicos integradores tanto de la casa letrada/nacional como el de la "gran familia puertorriqueñan ${ }^{n}$ que habita esas casas y las analogías que establecen las relaciones y jerarquías de sus versiones son el hilo conductor de mi lectura.

\footnotetext{
14 De acuerdo a Bakhtin:

The authoritative word demands that we acknowledge it, that we make it our own; it binds us, quite independent of any power it may have to persuade us internally; we encounter it with its authority already fused to it... located in a distanced zone, organically connected with a past that is felt to be hierarchically higher ... It is a prior discourse.

Ver "Discourse in the Novel" en The Dialogical Imagination (Austin: University of Texas Press, 1981) 342.

${ }^{15}$ Sobre este tema ver de Hayden White, Tropics of Discourse (Baltimore: John Hopkins University Press, 1978) y de Cornelius Castoriadis, La institución imaginaria de la sociedad (Barcelona: Tusquets, 1983).
} 


\section{VOZ PRIVADA, VIRTUDES PÚBLICAS: INSULARISMO}

¿Cuáles son las líneas argumentales de Insularismo? Fundar la biblioteca puertorriqueña, un archivo letrado de la historia y de la literatura nacional cuyo catálogo tendrá como punto de origen la labor de los autonomistas y abolicionistas y la publicación de El gíbaro de Manuel Alonso en 1849. En ambos casos se trata de las gestas del pensamiento liberal criollo decimonónico. Paralela a esta secuencia el ensayo se ocupa de la descripción de la comunidad nacional que, como "nave al garete" ha perdido la memoria de ese pasado y precisa su restitución para "enderezar su rumbo". El texto se propone, por lo tanto, como una escritura mediadora entre lo real y lo imaginario, entre el pasado y el presente, en búsqueda de "la significación oculta de los hechos que marcan la trayectoria recorrida por nuestra vida de pueblo" (Pedreira 25). Se propone, también, como una aventura de conocimiento y reconocimiento; un largo viaje cuyas coordenadas son el origen incierto que hay que rescatar y legitimar y el acceso a la plenitud criolla, la llegada al puerto seguro. Viaje y casa familiar, movimiento y permanencia, resumen la odisea textual y revelan el complejo entramado ideológico detrás de la versión de Insularismo: la voluntad y urgencia de los treintistas de permanecer como una voz confiable en una sociedad en proceso vertiginoso de cambio, y la resolución de modernizar y especializar el rol y el lugar del intelectual en esa sociedad.

\section{VOZ MAGISTERIAL}

La voz postulante del texto es el conductor de esa travesía, y su escritura es, como el viaje, un ejercicio itinerante, un diseño que busca llenar el sentido de la historia, dotar de una trama al conjunto inestructurado de los hechos. Ambos, viaje y escritura, interpelan al colectivo nacional para integrarlo a la versión propuesta en Insularismo y conjurar así la crisis de identidad que ronda ala ensayística delaépoca. PeroInsularismo le habla también, yreiteradamente, a "este país" localizando una voz narrativa que desplaza constantemente su foco del mundo referido al contexto discursivo del sujeto enunciante, a su lugar y temporalidad. No es sólo del pasado que se interesa hablar, sino de este presente y de este pais: al enunciar el relato del pasado se anuncia el relato del porvenir. No es, pues, el discurso cultural treintista nostálgico ni pasatista, sino una propuesta militante en lucha, frente a otras propuestas igualmente militantes, por la representatividad nacional. ${ }^{16}$

\footnotetext{
${ }^{16}$ Varios proyectos alternativos se disputaron una posición hegemónica en esas primeras décadas. Por un lado, el de la burguesía criolla vinculada a la tenencia de tierras, organizados en torno al Partido Unión (el sector hacendado) y el Partido Republicano (el sector cañero). Por otro lado, un sector profesional y/o financiero miraba hacia la nueva metrópolis como el eje de su proyecto y serian instrumentales en la fundación del Partido
} 
Desde ese campo tenso y polémico es que Insularismo organiza sus tretas argumentativas. La primera: autorizar su versión mediante el recurso a la voz magisterial atenuando, a la vez, el autoritarismo propio de esa voz. Su relato se valida situándose al margen tanto del retoricismo triunfalista de los defensores del progreso como de los saberes objetivos que produce la especialización: de la política, "ayer ... un deber patriótico; hoy es una profesión"; y de las ciencias y las estadísticas, disciplinas "sin alma". Se trata de "la más pura y desinteresada meditación", la cual se enuncia desde el ámbito de la cultura, una esfera no contaminada, pero influyente y decisiva en la formación de la opinión pública. En Insularismo “... la mejor manera de crearnos es padeciendo debajo del poder de la cultura" (Pedreira 175). La mejor manera, se lee entre líneas, es ejerciendo el poder de la cultura y desde esa posición, que reclama una autonomía relativa de otras zonas de la experiencia social, intervenirlas.

El paso por la casa cultural precede y legitima el traslado a la casa nacional, al espacio público, destino último de la privada y "desinteresada meditación". Ahí finaliza el viaje iniciático el cual provee su propia epifanía: una revelación que permita recuperar la memoria del pasado y restituir el orden y el sentido de la nación. El tono profético cesa y la voz magisterial propone su programa: alcanzar una autonomía cultural-nacional relativamente independiente de las formaciones políticas; lograr la nación, aún sin el estado. Este es, por lo tanto, un discurso nacional que, desde la subordinación colonial, es contestatario pero con aspiraciones hegemónicas. El medio: formar elites cultas capaces de denunciar a los enemigos de la nación y de guiar paternalmente a las masas ignorantes y utilitarias y así, entonces, poder edificar la casa del porvenir; trasladar el acontecimiento discursivo a acontecimiento social.

\section{EL SALON DE LECTURA}

El ensayo configura un salón de lectura, en el cual la "juventud dorada" escuchala lección magistral fundadora de la biblioteca puertorriqueña. Dirimida en la voz del Maestro, la lección asume la forma de un imperativo moral, un llamado a la conciencia y a la acción colectiva. ${ }^{17}$

Ese estilo doctrinario se había elaborado en el Ariel de Rodó, convirtiéndose en un tópico de la ensayística culturalista latinoamericana. De acuerdo a Roberto Gónzalez Echevarría sus paradigmas narrativos son: el aula, el

Liberal. Simultáneamente, un movimiento cultural y político obrero de orientación anarquista o socialista compartía ese escenario de debates, encuentros y negociaciones, organizados sobre todo, pero no exclusivamente, primero en la Federación Libre de Trabajadores y luego en el Partido Socialista.

${ }^{17}$ El valor atribuido a lo oral como connotación de la presencia -o como su espejismose opone a la escritura vista en una función instrumental y secundaria, "traductora de un habla plena y plenamente presente”. Ver Jacques Derrida, De la gramatologia (México: Siglo XXI, 1978) 13. 
maestro, las autoridades, la voz. ${ }^{18}$ El aula reunía dos condiciones fundamentales de la búsqueda de la identidad americana: presencia y conocimiento. La figura del Maestro sintetizaba la idea de la educación comola solución del pensamiento liberal criollo a sus proyectos para el porvenir. También esta figura, que presidió la mayoría de estos ensayos, se veía como el interprete más apto de la historia y la literatura de las distintas formaciones nacionales.

Aula y maestro configuraron la interioridad de estos discursos: el sistema de sus voces y autoridades. También fueron instrumentales en la demarcación de sus exteriores, que en el caso puertorriqueño fueron el imperialismo norteamericano, las corporaciones azucareras y sus propias masas asalariadas. Exteriores que se pretendían ajustar y subordinar al orden espiritual y a la jerarquía cultural organizadoras del gabinete.

Este lugar -como ficción discursiva一, donde la oralidad de la voz del Maestro como connotación de presencia e inmediatez se matiza en el saber fijo y atemporal de la Biblioteca, es, sin duda, uno de los mecanismos de control básico del discurso. ${ }^{19}$ El viaje intelectual parece desembocar ahí. No es hasta las últimas páginas que entramos plenamente a ese recinto del saber y conocemos la identidad de sus ocupantes, los narratarios del texto: los jóvenes universitarios que han de difundir la lección magisterial. Al reverso de la imagen de un pueblo como una masa infantilizada y domesticada, destinada a la mudez y el balbuceo, la figura del Maestro es la contrapartida necesaria del discurso patriarcal puertorriqueño, uno de los centros articulatorios del proyecto populista que pronto dominará el escenario nacional.$^{20}$ Maestro para los letrados, Padre para las masas desamparadas, a través de sus voces habla la nación.

\section{CAMINO A LA PURIFICACIÓN}

La voz profética se ha asegurado un tono, un espacio, y el medio de su difusión. El próximo operativo es purificarse, un proceso que se inicia con el saldo negativo de su generación:

18 "The Case of the Speaking Statue: Ariel and the Magisterial Rhetoric of the Latin American Essay" (The Voice of the Masters. Austin: University of Texas, 1985).

${ }^{19}$ Si bien la irradiacion de la voz implica movimiento - y, por lo mismo, temporalidadla biblioteca representa el espacio de la cultura. Ver de Gérard Genette "La littérature et l'espace" en Figures II (Paris: Seuil, 1969).

${ }^{20}$ La representací́n del pueblo como una entidad aletargada y desarticulada que debía ser conducida a su despertar fue un tópico común del discurso criollo tanto en su vertiente letrada como política. Su mejor exponente fue Vicente Géigel Polanco, un intelectual conectivo a la intelligentsia humanista, en la que se formo, y la intelligentsia técnica que formaria al pais. Ver de Diaz Quiñones, "Recordando el futuro imaginario" citado, y de Juan Gelpi "The Essay as Bildungsroman: Vicente Geigel Polanco's El despertar de un pueblon Ponencia leída en la Primera Conferencia de Poetas y Puertorriqueños en Nueva York, 19 de noviembre de 1988. 
De un modo, la cultura española hablando al sentimiento y de otra la norteamericana dirigiéndose al pensamiento ... cogida entre dos fuegos ... sin poder despejar la incógnita de su presente ... Al empezar el siglo XX, huérfanos ya de la madre histórica, quedamos al cuidado de un padrastro ricoy emprendedor (164).

En la misma se percibe una refracción interesante con respecto a las estrategias anteriores. No se trata solamente de ocupar un espacio, sino de desalojarlo, para (re)ocuparlo desde una posición más fuerte. El nosotros letrado toma distancia de sí mismo y se ve como una generación transeúnte que nace a la vida intelectual entre la ilusión de la prosperidad y su derrumbe.

Entre esas costas se mueve la nación como "nave al garete" auspiciando la identificación entre la nación y sus intelectuales. Ambos participaron de la misma culpa y un mismo mal moral los aqueja. Se han desnaturalizado al desatarse los lazos familiares propiciando la carencia y la orfandad. La nueva metrópolis se representa como el padrastro, una figura de impostación que no puede sustituir la figura materna y sus connotaciones de origen y protección, y el reemplazo provoca la pérdida de la visión. El país carece de dirección. Los jóvenes elegidos, los que no han participado de la entrega y de la disolución moral, son los llamados a restituir el rumbo y la coherencia. Una condición previa se impone. Emprender, a la par que la nación, el camino a la purificación: “... dar audiencia a nuestros pecados y defectos y preparar el curso de las obligaciones a través de firmes propósitos de enmienda” (163).

Como ha identificado Arcadio Díaz Quiñones en su ensayo "Recordando el futuro imaginario" la narrativa histórica de los años treinta se monta sobre la existencia de tres tiempos que corresponden a los orígenes, la caída y la resurrección. Así, aunque la caída produzca un vacio nacional, éste puede llenarse con el discurso de los letrados. Entonces, y desde el terreno cultural, se puede renacer. Ésa es la tarea, una misión ética que, expresada en un lenguaje médico, curativo, se traduce en un acto regenerativo “... inyectar sanidad, sangre nueva, optimismo y alegría en el cuerpo desgastado de la sociedad" (Pedreira 170). Y esa misión sólo la puede desempeñar el que, ajeno al desgaste, pueda reconocer la versión letrada lista a proyectarse en los elegidos: “... los hombres de mi generación hemos buscado inútilmente un hombre superior a nuestras luchas intestinas, a cuya sombra acogedera y pura pudieramos oír con claridad la voz de nuestro mito ... ¡Un Maestro!" (Pedreira166). ${ }^{21}$

\footnotetext{
${ }^{21}$ El uso de categorías míticas, como es el caso de la alegoría religiosa que Díaz Quiñones señala en la construcción de la temporalidad de la historicidad puertorriqueña, es otra estrategia de uso extendido en la ensayistica nacional. Le permite transferir el prestigio y la au toridad de un lenguaje sacralizado, como es el de los orígenes, a relatos que son de comienzos, un concepto cuya temporalidad es de orden secular. Sobre esta distinción ver de Edward Said, Beginnings: Intention and Methods (New York: Basic Books, 1975).
} 
La voz que enuncia el texto se asegura ese lugar. Desde ahí genera tanto los mitos de orígenes como de continuidad que anuncian la casa del porvenir. Su voz tenderá el puente que permita superar la carda. Sin embargo, aún subsiste un obstáculo que vencer. La purificación no se consume en el tránsito por la alta cultura, otras voces se escuchan y necesitan ser acalladas. Voces disidentes de las cuales Insularismo borrara sus distinciones internas igualándolas en la carencia común. Ajenas, sordas a las palabras del Maestro, desafinan en el gabinete de lectura y son las voces impuras que perpetúan la caída. Para imponerse como la voz redentora la voz profética precisa, entonces, impedir la circulación del discurso del otro. En una obvia alusión a los debates políticos de su momento se afirma:

... de la mecha socialista y del pico del águila republicana y de la trompa del elefante coalicionista ha cádo sobre nuestro pueblo un deterioro de frases lapidarias capaz de empedrar el camino del infierno (117). ${ }^{22}$

Voces que hay que silenciar para que el reclamo de defensa del bienestar colectivo y del capital cultural de la nación quede en manos del discurso "desinteresado" de los letrados..$^{23}$ Ante la caída y la degradación la cultura es regenerativa: sólo ella puede sanear la nación y anunciar un tiempo nuevo.

\section{EL RELATO}

Ahora hay que reconstruir las tierras de la memoria que quedaron baldías en el noventa y ocho, fecha de la caída. "Todo está por hacerse", reclama el texto. A la carencia de voz se suma un país sin historia ni literatura, al "mar muerto de sus letras", "siglos en blanco para nuestra historia". La insistencia en el vacío y la carencia subraya la necesidad de poseer un pasado relatable que permita no sólo describir al país; también hacer el país. Así, pues, constituida la voz de la nación se le entrega su guión, el cual informó nuestro imaginario como pueblo hasta que la tumultuosa década del setenta puso en peligro su larga hegemonía.

Surgía de los textos treintistas, y en particular de Insularismo, el relato de una nación de filiación hispánica, católica, defensora de la pureza de la lengua y respetuosa de las jerarquías sociales. Un relato de continuidad y de armonía social que, al elegir y erigir unas secuencias históricas y literarias fundaba su

22 Se refiere al gobierno de coalición entre el Partido Republicano — de orientación anexionista-y el Partido Socialista a partir de 1929.

${ }^{23} \mathrm{El}$ desinterés como denegación de la lógica de la economía capitalista es uno de los conceptos capitales del discurso culturalista. Sin embargo, de acuerdo a Pierre Bourdieu, las leyes de funcionamiento de los bienes culturales funcionan como un capital simb́lico, un capital de consagracion que es generado, y a su vez genera, prestigio y autoridad (op. cit.). 
linaje cultural y político. Un relato que distribuía los lugares y los sujetos del pasado mientras excluía otros linajes del campo de la representación nacional. El proceso implicó dos operativos: la resemantización de elementos del pasado desde la perspectiva del presente y su activación en la producción de nuevos discursos y representaciones. También, loque Eric Hobsbawn llama lainvención de la tradición, la creación de nuevos ritos y gestos culturales propuestos como la memoria cultural colectiva de la nación. ${ }^{24}$

La "voz de nuestro mito" se ajusta a los imperativos de ese proceso: a la "ordenación y selección de los elementos de ayer y de hoy que nos convenga guardar para mañana" (Pedreira, 164). Tradición y continuidad; la posibilidad de permanecer en el cambio. El ensayo se apresta a trazar sus analogías a partir de una premisa inicial: el XIX fue el siglo criollo y su ritmo ascendente se detuvo en la "catástrofe" del noventa y ocho. En ese momento cesó el "rumbo de la historia" y su movimiento se descompuso en el "gesto interrumpido", desarticulador del sentido de la unidad nacional. El intérprete de la nación fueron los criollos y la voz letrada del presente es, a su vez, herededera e intérprete de esos criollos, responsables de: “... las demandas -el despertarde nuestro derecho colectivo, que desde entonces hasta ahora han sidoformuladas por los hijos del país" (Pedreira 21).

Otra serie analógica acompaña este friso de héroes: sus gestas. Se trata de “... recoger los elementos dispersos que laten en el fondo de nuestra cultura y sorprender los puntos culminantes de nuestra sicología colectiva" (Pedreira 25). El binarismo de la serie - lo alto/lo bajo-duplica otra oposición que habíamos trazado en el gabinete de lectura: el exterior/el interior. Alerta al lector sobre los códigos ideológicos que orientan el ensayo: por un lado, y central a la versión histórica propuesta, el principio del consenso y de la homogeneidad; por otro lado, y en los márgenes o silencios de esa versión, la heterogeneidad y la fragmentación, su otredad radical, sin la cual no sería posible postular su identidad. Los "puntos culminantes", unidades totalizantes, deben imponerse a la fragmentación, a "los elementos dispersos"; los héroes y las gestas criollas a la mezcla racial, el determinismo geográfico, el cambio de soberanía, el imperio del azúcar y los efectos de la modernidad. Todos aquellos elementos no asimilables en la versión criolla de la nacionalidad serán filtrados, depurados, en la ordenadora.

Ante el embate de la modernidad era hora de reorganizar la casa, no ya la casa de la cultura, el salón de lectura como espacio de enunciación de esa trama integradora, sino la casa nacional, sede de las tradiciones legítimas del país. El uso de la metáfora filial facilita la identificación que extiende la idea de la

\footnotetext{
${ }^{24} \mathrm{El}$ proceso incluye tradiciones:

.. actually invented, constructed and formally instituted and those emerging in a less easily traceable manner within a brief and dateable period ... and establishing themselves with great rapidity"

en The Invention of Tradition (Cambridge: Cambridge University Press, 1983) 1.
} 
familia patriarcal, como paradigma natural de la vida social, a la constitución nacional. De esa manera se viabiliza la permanencia de relaciones sociales y culturales tradicionales en un momento de cambio acelerado familiarizando, a su vez, el proceso de modernización. La nación la habita el patriciado criollo recuperado como una figura de orden y acción y un grupo familiar supeditado a ese centro. A diferencia de ese patriciado que sí tiene nombre y apellido, las figuras subordinadas son anónimas. Se agrupan sin distinción alguna; son "una muchedumbre dócil" y "cortésmente pacífico como nuestro paisaje" (Pedreira 48). Por otro lado la figura femenina se identifica con la tierra y, por extensión, con la idea de génesis y de violación. Los criollos son "fruto con sabor a tierra" y el paisaje es "tierno, blando, muelle, cristalino y ... femenino" (48).

La función de lo "femenino" y sus connotaciones telúricas debe ser destacada en estas retóricas nacionales cuyo centro de enunciación lo fue unaintelectualidad urbana y masculina. Su inserción en el discurso completa la composición de la casa nacional mientras apoya la idealización del mundo campesino en oposición a lo urbano - representado como el espacio de lo heterogéneo, de lo múltiple y de la dispersión. La casa nacional, modelada en un conjunto de normas y valores tradicionales atribuidos al agro, y restaurada por los lazos filiales que unen a los criollos del pasado con los del presente, se legitima como la reserva moral del país. La figura femenina es el enlace necesario en esa gestación de la nacionalidad.

Concurrentemente a la idea de génesis, la violación es su contrafigura necesaria. El paisaje "femenino" está sujeto a ser devorado por el cañaveral, una figura usurpadora y ajena al ámbito familiar, que asume constantemente marcas masculinas en el texto. Identificado con el capital azucarero y norteamericano, el cañaveral varía y agrede lo que se pensó inmutable y eterno: los elementos del paisaje, pero también el rumbo de la historia. La urbanización de lo real es una presencia perturbadora que destruye la fisonomía de la casa nacional nivelando y disolviendo progresivamente el andamiaje paternalista de su sistema de relaciones. El éxodo obligatorio a la costa, al que obliga el derrumbe económico de la montaña y el avance urbano del latifundismo cañero sobre la pequeña tenencia de tierra hace exclamar a la voz autorial de Insularismo: “... ante su empuje van desapareciendo los bohíos, como desaparecieron los pantanos, las haciendas, los ingenios ... y el camino real" (Pedreira 48). También desaparecía un estilo de convivencia social amenazado por el fantasma de lo urbano y su diversidad social y cultural. "El amo de la tierra es el amo de la patria" sentenciaba Manuel Zeno Gandía en esos años. Insularismo anuda sus historias:

Es curioso notar que el aspecto económico de la tierra varía distintamente de acuerdo con los tres momentos en que dividimos el curso de nuestra historia. En el primero, pausado y unitario, los repartimientos y las encomiendas hacian de ella una vasta finca, a medio cultivar... En el segundo, inquieto y decisivo, se fragmenta en abundantísimas parcelas ... $\mathrm{Y}$, en el tercero, indefinido $y$ problemático, la tierra pierde su pequeño propietario (52). 
"La tierra se nos va de las manos sin sentirla" (Pedreira 47), se lamenta el texto, y en ese desarraigo de la tierra se acentúa la orfandad de la nación en un relato fundamentado en un doble registro de la pérdida: de estar perdidos como "nave al garete" y de haber perdido, de haber sido desposeídos. La explotación de la tierra -Madre/Mujer - se ve como una violación al patrimonio familiar. ${ }^{25}$ Y esto siempre desde la perspectiva del agresor masculino: el "padrastro rico y emprendedor" (el imperialismo norteamericano) que desplaza a la madre natural (la colonia española). Renacer implica, por lo tanto, no sólo regenerar, sino también fecundar, restituir a la (re)productividad. Sembrar la nación de hijos criollos, de "frutos con sabor a tierra". La figura femenina es la imagen que posibilita tanto el origen como la continuidad, la generación y la regeneración. Tarea imposible sin la intervención masculina. La voz letrada es la semilla fecundadora responsable de "... cultivar ideas y sentimientos viriles. De no aumentarnos estaremos condenados a la ingrata condición de peones"(Pedreira $50)$.

Si la imagen del Padre/Maestro detenta y reclama ser el lugar de elaboración del discurso nacional, la imagen de la Mujer/Madre auspicia su transmisión. Ella es figura recipiente, canal de transmisión natural y legítimo de la tradición que impone la figura masculina, agente activo en ese proceso. Desde esa perspectiva se explica la condena que el texto hace de la mujer como figura pública y su reducción al ámbito doméstico: "Misión política - iy tan patriótica!es la de ayudar a formar, entre nosotros, a la perfecta dueña de casa, tan responsable de la industria, de la agricultura y del comercio nativo" (Pedreira 109).

La versión histórica asume, pues, la forma de una narrativa familiar que, alterada por la caída/ violación, lucha por reintegrarse y (re)establecer la armonía natural y originaria. De ese modo, la homología entre familia-nación viabiliza que las estructuras de las relaciones familiares tradicionales expliquen e iluminen la historia nacional.

Autorizada la voz, constituidas sus casas, éste es el momento de mostrar las pruebas fehacientes de la memoria colectiva, su álbum familiar. La historia y la literatura, el terreno de mayor autonomía en la nueva configuración letrada, se complementan y concurren en la formación de la esencia criolla. Se percibían como un modo propio y manejable - familiar- de especialización, opuesto a otros discursos especializados surgidos de la experiencia modernizadora.

Los patriarcas asumen nombre y apellido. Los hombres representativos de Pedreira son un "... puñado de nombres que nos representan en casi todos los compartimientos insulares de la cultura":

\footnotetext{
${ }^{25}$ Sobre este tema ver de Doris Sommer, One Master for Another (New York: University Press of America, 1983), sobre todo el primer capitulo "From Romance to Novel: Populism as the Rhetoric of Frustrated Loven, 1-49.
} 
Hemos dado a las armas extranjeras nombres gloriosos como los de Rius Rivera y Pachín Marín ... a la hagiografia una mujer ilustre: Santa Rosa de Lima; a la ciencia jurídica un tratadista venerado en toda América: Eugenio María de Hostos, a la mar dimos a Ramón Power y al pirata Cofresí; a la botánica: Stahl ... Cuando yo me pregunto por la honradez patrítica, señalo en primer lugar a Baldorioty; cuando busco un carácter lo encuentro en Ruíz Belvis o en Betances; una mente filosofica; Matienzo o Lopez Landrón; un periodista; Brau - Muñoz Rivera ... (Pedreira 42):

A este catálogo de nombres representativos le corresponde el de sus gestas, el compendio de la historia criolla, que con el nombramiento de Ramón Power a las Cortes de Cádiz en 1809 inicia:

... la aparición de la prensa independiente, diversos levantamientos populares, iniciación de la literatura nativa, abolición de la esclavitud, informaciones en Cortes, desarrollo de la instrucción pública, surgimiento de los partidos políticos, conciencia de ser puertorriqueños antes que nada, fundación del Ateneo, etc. hasta que cuaja en la efímera autonomía concedida en España en 1897 (83).

$\mathrm{El}$ deslinde muestra una visión cultural definida en torno a los signos de la alta cultura: acceso a la letra -la prensa y la literatura criolla-y los estilos organizativos e institucionales del pensamiento liberal -los partidos y el programa de reforma. Las acciones que no registraron nombres, ni textos quedaron fuera de ese listado: las revuel tas de esclavos e inclusive el movimiento separatista, reducido a un mero renglón en el ensayo, como el Grito de Lares, un "cariñoso recuerdo", desnaturalizado de su violencia revolucionaria.

Dotada de una historia, la nación se constituye finalmente en su capacidad para expresarse culturalmente. Son "las sensibles placas del arte literario", dice Pedreira, el punto donde "se proyectan el hombre y sus contornos" (56). La afiliación a una tradición intelectual humanista que contribuyera a la afirmación de la identidad se convirtió en un imperativo de la emergencia del campo intelectual treintista. Simultáneamente se fundaba una poética-el criollismo, y con ella, tanto el conjunto de sus textos como el canon de su lectura.

En 1849 -y con la primera edición de El Gíbaro de Manuel Alonso- "las iniciales de nuestros comienzos" se expanden admitiendo, junto a los nombres y apellidos del patriciado criollo, el registro de sus bienes. Los ocupantes de la casa familiar empiezan a escribir su historia y, en ella, a leerse a sí mismos. "El triunfo de Alonso fue completo: el criollismo salvó al fin su primer libro sagrado", afirma Pedreira (60). El Gíbaro, como el "primer libro sagrado" del criollismo, y el autonomismo, como el "resumen glorioso" de sus gestas, representan la plenitud que precede la caída y que la escritura del presente intenta rescatar que puede hacer frente a la amenaza externa e interna.

El criollismo se invoca como factor de unidad cultural e histórica. En el pasado se impuso a lo que considera el sentimentalismo medroso de Gautier Benítez que "ni penetró en el pueblo y sus costumbres" (63) y al cosmopolitismo 
veleidoso de Tapia y Rivera cuyos textos "no tienen la sazón de nuestra biologia y nuestra geografia" (62). En el presente el criollismo modera la estridencia de las vanguardias, reducidas al "gesto rebelde de unos jóvenes que no pueden conformarse con los antimacasares literarios de nuestros abuelos" (66). a la vez que se distancia de la "jibarada literaria (que) estorba mucho cuando no suele ser de largo alcance" (69).

Así, la serie literaria participaba del mismo diseño narrativo que organizaba la historia de la nación; un entramado de inclusiones y exclusiones elaborados a partir de series antagónicas -adentro/ afuera; alto/ bajo; culminación/ dispersión. Un entramado donde la escritura letrada se propone como el enlace que armoniza esas series, concilia los opuestos. "Todo está por hacer". Con esa advertencia el investigador inicia su viaje al pasado en la búsqueda de los arquetipos de la nacionalidad: descubrir el gran diseño de la cultura nacional oculta por el "campo de niebla" que tendió la caída. No hay "una obra de conjunto sobre la literatura puertorriqueña". Si bien la tarea de los criollos del pasado fue el quehacer cultural, la nuestra es registrarla, consolidarla en memoria cultural; adivinamos tras esas palabras:

... los escritores del siglo XIX no pudieron contestar a sus anchas las preguntas de su época: detrás de ellos no había sino un hueco desolador de tres siglos baldíos y enfrente una esterilizadora vigilancia que no les permitía empollar ademanes patrios, ni subir la fiebre de nuestra personalidad colectiva a sus cuarenta grados (64).

La voz profética de Insularismo vence la esterilidad. Ante sus ojos se despliega el siglo criollo como un territorio virgen para el investigador, "nuestra inviolada producción literaria", que los letrados del presente fecundarán. Recogida la cosecha, el ensayo se apresta a otra fabulación en la cual la voz privada del gabinete de lectura revelará sus virtudes públicas.

\section{EL PROGRAMA}

El relato del pasado ha vestido la memoria de un linaje, de una historia cultural que se ofrece, redimida, al cuerpo de la nación. Puestos los cimientos, ahora se trazan los contornos de la casa del porvenir. Como en el relato del pasado, la estrategia de legitimación es similar: desautorizar y neutralizar las líneas de disensión para entonces proponer un programa de unidad y armonía social.

A la voracidad del capital extranjero se añade el surgimiento de otros sectores y escenarios sociales que escapan a la arquitectura del relato letrado. En el patio del caserón antillano, lugar del orden, de la unidad y la continuidad, se escucha el rumor creciente y ensordecedor de la masa que habita en "las costas que ... aprietan como ergástulas" y "en las perpetuas factorías de tabaco y melaza". Pero ésta carece de una historia relatable, de un álbum familiar que 
le permita constituirse nacionalmente. Su lugar en el relato criollo es de subordinación o de un añadido molesto o necesario. Es también los límites de ese relato, un recordatorio de los gestos de la barbarie que intenta inútilmente borrar. Lo corroen los signos de disensión y ruptura que representan las diferencias raciales y sociales al interior de la propia casa nacional. Espacios conflictivos que desafían el paternalismo de la voz profética y que, heterogéneos y anónimos, representan el hiato de la sintaxis ordenadora. No es de asombrar, entonces, que la "más pura y desinteresada meditación" tenga como enmarque narrativo un enunciado de ordenación racial que la inicia y un enunciado de ordenación social que la clausura.

Por otro lado, la prisa, el lleno, el número-signos de lo urbano y del proceso modernizador-entran en el discurso treintista como una presencia perturbadora que debe ser sofocada. El "sentido económico de la vida" hace que del "ocio creador" se pase al "tiempo es dinero", arrasando con las viejas formas e instituciones de sociabilidad intelectual. Mientras, la isla criolla abandona su forma familiar y se amolda a los contornos del "imperio del dinero"; "... las antiguas casas solariegas, con amplitudes de almacén, han dado paso a la hermética vivienda, apretadamente construida para economizar costoso espacio" (Pedreira 94). Empequeñecimiento físico, empequeñecimiento espiritual, el solar letrado se reduce.

Pero es la alteración del número su mayor amenaza. El “justo medio", la democratización modernizadora que habilita el acceso de la muchedumbre a la vida pública y a las instituciones de la alta cultura: "Con iguales oportunidades para todos, la plebe se ha sentido satisfecha al ver subir sus valores a costa del descenso de los hombres cultos" (Pedreira 91). Urge, por lo tanto, detener la aglomeración que subvierte lo alto y lo bajo, el adentro y el afuera de la versión letrada. Urge regimentarla en un nuevo pacto social que respete las viejas relaciones de poder y que aliente la "colaboración extraor dinaria de los selectos".

Se trata de un programa de conciliación dirigido a la comunidad nacional, pero digitado por una minoría culta. La escena es ocupada, ahora, por la "juventud dorada", los jóvenes universitarios destinatarios de la lección magistral. Desde el control de los centros educativos y culturales del país deben intervenir activamente en la vida política del país y aminorar el ascenso de las masas. Deben reproducir el gesto paternal: tender "sus manos fraternales hacia ese lote obrero y burocrático que necesita intercambiar sus angustias y ensanchar las zonas de su gremio" (Pedreira 170). Ellos serán la garantía de continuidad del relato de la nación y los forjadores de la casa del porvenir.

\section{DE LA CASA A LA CALLE}

toda fundación aviva la esperanza, esa nostalgia del porvenir, ese recuerdo de lo jamás logrado. (Edgardo Rodríguez Juliá, La noche oscura del niño Avilés). 
A jóvenes letrados se dirige también el primer ensayo de $E l$ país de cuatro pisos. Si Insularismo cristalizó una ideología cultural representativa, en gran medida, de los debates y de la dinámica de un sector del campo intelectual afiliado a la burguesía criolla en crisis, $E l$ país de cuatro pisos responde, también, a reordenaciones importantes del campo intelectual del presente, y a otro momento de crisis tanto social como cultural.

Un hecho era evidente: el viejo orden, impuesto primero por el populismo de los cuarenta y luego por el desarrollismo de los cincuenta, y legitimado, en gran medida, por la versión histórica de los textos treintistas, se desplomaba. Mientras, José Luis González extendía el círculo de sus lectores y maquinaba la construcción de su país de cuatro pisos, el cual albergaría en sus modernas habitaciones una vieja familia extendida: la familia puertorriqueña.

Como en los difíciles años de las primeras décadas, la vertiginosidad del cambio hacía irreconocible el rostro del pais. Pero, a diferencia de aquellos letrados, el afán interpretativo no condujo a las arcas de un pasado idealizado sino a la turbulencia del presente. Desde finales de los años sesenta un afán desmitificador dominó el espíritu de la época, y uno de sus objetivos fue enfrentarse a la memoria cultural que tan celosamente tejieron los treintistas. Nuevo fue el calificativo más deseado: nueva canción, nuevo teatro, nueva historiografía, nueva literatura, nueva gráfica y una nueva lucha sindical y política alentada por los avances de la izquierda en la experiencia de la descolonización de Africa y el Caribe, la Guerra de Argelia, la Guerra de Vietnam, los sucesos del '68, la Revolución cultural china y, sobre todo, la Revolución cubana. Sucesos que generaron la ilusión de que el cambio era posible y, aún más, necesario e impostergable. Por otro lado, con la presencia de otros protagonistas sociales - la creciente clase media y la proletarización de sectores tradicionalmente artesanales y agrícolas_ surgían nuevos lectores y nuevas demandas culturales, entre ellas ser incluidos en las nuevas versiones históricas.

Ante ese panorama losintelectuales no escaparon de la gran utopía cultural de la izquierda latinoamericana de esos años: homologar vanguardia artística y vanguardia política; pensar que entre la realidad y el arte existe una relación intercambiable en la cual teoría y praxis cultural debían conformarse a las prácticas sociales. "La realidad se nos revela cargada de poesía" declaraba en su primer editorial una de las revistas faro de la época: Zona carga y descarga, y el intelectual se localizaba en relación a las zonas populares, convertido ahora en interlocutor e intérprete de sus discursos.

El ensayo de González, como el de Pedreira en su momento, es testimonio de la reorientación de su campo intelectual. Es también un diálogo con la versión cultural y nacional hegemónica como con otras formas de la disidencia: por ejemplo, su defensa del marxismo y su crítica al nacionalismo. Su propuesta, la idea de una nación mulata y caribeña y la sobrevivencia de la cultura popular sobre la cultura de élite impugnaba los pilares de la memoria 
cultural dominante y postulaba, concurrentemente, una contramemoria que colocaba en su centro los sectores sociales previamente confinados a los márgenes. El "alma puertorriqueña, disgregada, dispersa, en potencia, luminosamente fragmentada, como un rompecabezas doloroso que no ha gozado nunca de su integridad" de Insularismo, se escindía ahora por la lucha racial, económica y política. Un corte que se practicaba desde una zona descartada por los treintistas y recuperada preferentemente en la nueva configuración letrada: la política; y ésta como un terreno capaz de dar cuenta tanto de sus propias zonas de influencia como también de otras experiencias sociales: la expresión cultural entre ellas. Escribe González:

En toda sociedad dividida en clases, la relación real entre dos culturas es una relación de dominación ... Y lo que se presenta como "cultura general", vale decir como "cultura nacional", es, naturalmente la cultura dominante. ${ }^{26}$

El examen de las formaciones sociales y económicas, esquivado en Insularismo es el centro de su propuesta cultural y nacional. Con ellas se liberaba del tono sacralizador que había acompañado y prestigiado la reflexión nacional. Además, en su versión, los herejes - los "grifos parejeros" de Insularismo - se apropiaban de la historia: nombraban su linaje y construian su casa del porvenir. Veamos su arquitectura.

Un primer piso antillano caracteriza los siglos XVI y XVII y su personaje representativo sería el puertorriqueño negro, incapaz de desplazarse por su condición esclavay, por lo tanto, el elemento estable y fundador de la nacionalidad. Le sigue un segundo nivel montado sobre las corrientes inmigratorias del siglo XIX. En su mayoría peninsulares - sobre todo corsos y mallorquíes-y exilados de las guerras libertarias de América Latina, se asientan preferentemente en la altura, en la zona cafetalera, desplazan a los colonos - los “jibaros" de la montaña-y "blanquean" la composición racial dominante hasta ese momento. Fundan un mundo señorial y patriarcal y se constituyen, a finales del XIXen los "hijos del país" de Insularismo: artífices del proyecto criollo que, prácticamente, alcanzan con la obtención de la Carta Autonómica de 1897. La intervención norteamericana de 1898 canceló esa ilusión de poder - ser socios en la administración colonial- y constituye su tercer piso. El último lo es, según González, la crisis actual “... el resquebrajamiento espectacular e irreparable del cuarto piso que el capitalismo tardío norteamericano y el populismo puertorriqueño le añadieron a la sociedad insular a partir de la década de los cuarenta" (40).

En ese proceso el relato de continuidad se sostiene en la presencia constante del negro, ya fuera el esclavo del pasado como el "grifo parejero" del presente.

${ }^{26}$ José Luis González, El pats de cuatro pisos (Río Piedras: Huracán, 1980) 12. Indicaré número de página a continuación de la cita. 
También, en la sobrevivencia de la cultura popular producto de la interacción de elementos campesinos y afroantillanos:

... pero con claro predominio de la vertiente afroantillana por razones demográficas, económicas y sociales. Empero, la actitud conservadora asumida por la clase terrateniente marginada desnaturalizó esta realidad a través de su propia producción cultural, proclamando la cultura popular del campesinado blanco como la cultura popular por excelencia (38-39).

Apropiación que se invierte en el '98 y la cual sirvió “... a la masa popular para impugnar y desplazar los valores culturales de la clase propietaria" (36). Este tema se desarrolla en otro ensayo de la misma colección, "Plebeyismo y arte en el Puerto Rico de hoy", un ensayo que junto a "Literatura e identidad nacional en Puerto Rico" es central para cualquier estudio sobre propuestas literarias e interpretativas en nuestra cultura, un tema apenas abordado en este trabajo.

La versión de "El país de cuatro pisos" trastornaba radicalmente los contenidos ideológicos de la propuesta treintista y su resonancia en los proyectos y debates contestarios lo ha mostrado así, fijando hasta cierto punto sus posibilidades de lectura. ${ }^{27}$ Sin embargo, su andamiaje retórico no escapó totalmente de las estrategias discursivas propias de metanarrativas nacionales. Reconocibles son: la inscripción de la voz magisterial como una voz autorizada $\mathrm{y}$ autorizable, el recurso al linaje heroico y al archivo letrado del XIX - su relectura de Hostos y Tapia y Rivera, por ejemplo, aun cuando su versión se propone como recuperación de la cultura popular-y el gusto por la imaginería arquitectónica en su figuración de la nación. También la creación de otra mitificación de lo nacional para los nuevos usos e intereses del nuevo equipo intelectual. Esbozo esas líneas de argumentación.

El ensayo se inicia con la lección magistral que, a pesar de ser dictada para "jóvenes estudiosos de las ciencias sociales", aspira a la comunidad nacional como su destinatario real. El ensayismo se prestaba, una vez más, a ser la escritura ordenadora de la experiencia social. El aula de El país de cuatro pisos se compone ahora de los textos excluidos o subordinados de la biblioteca de Insularismo: son los disidentes del reformismo liberal y autonomista del friso de héroes treintistas. Inclusive, cuando coinciden, una relectura diferenciada los separa. Eugenio María de Hostos cesa de ser el sociólogo y maestro admirado por Pedreira y se convierte en crítico de la "barbarie" del régimen colonial español. En otros casos invierte lugares. Así, en la revaloración que sobre el origen de la literatura nacional hace en "Literatura nacional en Puerto Rico", el criollismo de Manuel A. Alonso y El gíbaro es desplazado por la escritura

${ }^{27}$ Inclusive en lecturas críticas como las de Ángel Quintem "Historia de unas clases sin historia para el análisis cultural", CEREP 6 (septiembre 1983) y Juan Flores "The Puerto Rico that José Luis González Built" (inédito). 
modernizadora y cosmopolita de Alejandro Tapia y Rivera, más afín al proyecto intelectual de González.

Con un programa de restitución para la nación cierra el ensayo de González: “... tenemos una tarea que consiste, ni más ni menos, en la reconstrucción de la sociedad puertorriqueña" (42). Y, aunque advierta enfáticamente: “... no podemos combatir esa mitificación con otra mitificación", refiriéndose a la propuesta treintista, la disidencia fundaba sus propios mitos: la actualización de la Federación Antillana que propusiera Betances en el XIX y que en su nueva versión enfatiza, ahora, el componente afroantillano.

De ese modo, los fundamentos de la propuesta treintista no se destituyen del todo; parecería, más bien, que se invierten sus términos. Sin embargo, en esainversión sellaba su suerte y, así, el ensayismo cultural sobre la nacionalidad, al menos en sus contenidos treintistas, quedaba finalmente atrapado en los cuatro pisos que González le echara al país.

\section{CODA}

Una última reflexión se impone. ¿Cierran con este gesto las casas del porvenir? Aunque aún insuficientes, los trabajos críticos tanto en historia como en literatura, así como las nuevas orientaciones que rigen los trabajos de ficción, muestran otras fachadas. Sugieren que ya no es posible la identificación sostenida de lo nacional con el discurso integrador y totalizante de las metanarrativas que dominaron la escritura de la modernidad social y literaria iniciada en el Puerto Rico de las primeras décadas de este siglo. Al contrario, estos textos - tanto narrativos como poéticos- convocan a la relectura y reescritura de los paradigmas interpretativos centrales de una memoriacultural que, cristalizada en los textos y acciones de la primera generación cultural forjada en los sucesos del '98, y debatida luego por las generaciones disidentes de esa memoria, apenas se aferra a sus cimientos. Son signos de un proceso que incita a enfrentarse crítica y creativamente e, inclusive, a desconstruir la retórica, las zonas de influencia y las prácticas interpretativas de aquellas metanarrativas. Es, por lo tanto, una literatura en tránsito a un nuevo espacio irreverente y diseminador tanto de un sentido como de autoridades centrales.

De esos textos y de otras prácticas culturales emerge ahora una diversidad de imágenes y versiones que configuran lo puertorriqueño como un espacio social y cultural heterogéneo, fragmentario y contradictorio, un "país de muchas tribus", como lo llamaría un joven narrador. ${ }^{28}$ A la dialéctica de las oposiciones binarias que oponían, entre otras relaciones, el adentro/afuera y el nosotros/

\footnotetext{
28 ¿Familia puertorriqueña o país de muchas tribus? ... La mitologfa a que nos obliga la muchedumbre se desmorona; esa cursilona ideologia, que casi nos convence del ilusorio valor de creernos familia aquí se desmorona ...", Edgardo Rodríguez Juliá, El entierro de Cortijo (Río Piedras: Huracán, 1983) 90.
} 
ellos de esas casas del porvenir lo sustituye ahora otro modelo relacional: el dialogismo de una difícil, pero no menos fascinante pluralidad, que lejos de cerrar el debate de lo nacional lo abre a otras casas y otras calles de esa comunidad imaginaria que llamamos nación. 